\title{
Separate and shared lysosomal transport of branched and aromatic dipolar amine acids
}

\author{
Barbra H. Stewart ${ }^{1}$, Ellen J. Collarini ${ }^{1, *}$. \\ Ronald L. Pisoni ${ }^{2}$ and Halvor N. Christensen ${ }^{1}$ \\ 'Department of Biological Chemistry and " Department of Pediatrics and Communicuble Diseases. \\ The University of Michigan Medical School, Ann Arbor, MI (U.S.A.)
}

(Received 11 July 1989)

Key words: Lysosomal transport; Amino acid transport; System L: System T

Transport systems analogous to the $T$ and $L$ carriers for aromatic and bulky dipolar amino acids in plasma membranes have been characterized in the membranes of intact lysosomes isolated from human fetal skin fibroblasts. While system $\mathbf{L}$ appears ubiquitous in plasma membranes, system $T$ has previously been discriminated only in the plasmalemma of human red blood cells and freshy isolated rat hepatocytes. Our findings with the lysosomal systems, provisionaily designated $t$ and $l$, reveal both shared and dissimilar properties with the plasma membrane systems. These properties include a lack of dependency on extralysosomal $\mathrm{Na}^{+}$, differential sensitivities to the classical system $\mathbf{L}$ analog, 2-aminobicyclo|2.2.1|heptane-2-carboxylic acid (BCH), and the system $T$ analog, D-tryptophan, as well as susceptibility to thiol modification at the membrane by reactivity with $\boldsymbol{N}$-ethylmaleimide. A transport system in lysosomes from the FRTL-5 rat thyroid cell line has been described by Bernar et al. ((1986) J. Biol. Chem. 261, 17107-17112) resembles a composite of both carrier systems reported in this work.

\section{Introduction}

Evidence that the transport of bulky, dipolar ('neutral') amino acids across plasma membranes is heterogeneous in nature has been reported for human red blood cells [2-4], for isolated rat hepatocytes [5] and for freshly isolated versus primary culture hepatocytes [6]. In red blood cells and isolated hepatocytes, the ubiquitous system $L$ carrier for bulky dipolar amino acids is supplemented by a second agency, termed T. This second carrier system is more selective for aromatic amino acids, in general having higher affinity for Trp, Tyr and

\footnotetext{
* Present address: Department of Biology (Msdawar Building). University College London, Gower Street, London WC1E 6BT, U.K. Atbreviations: All stereorsomers of natural amino acids are $L$ unless indicated otherwise. Standard three-letter abbreviations are used for the amino acids. $8 \mathrm{CO}, \approx-3$-aminnhicyclo 3.2.1 loctane-3-carboxylic acid; BCH, b(-)-2-aminobicyclo[2.2.1 heptane-2-carboxylic acid; NEM, $N$-ethylmaleimide; MeAIB 2-methylaminoisobutyric acid; Mops, 4-morpholinepropanesulfonic aicd; Mes, 4-morpholineethanesulfonic acid; LME, L-leucine methyl ester; TME, L-tryptophan methyl ester; hex, hexosaminidase: PBS, phosphate-buffered saline.

Correspondence (present address): B.Il. Stewart, Drug Metabolism Department, The Squibb Institute for Medical Research, P.O. Box 4000, Princeton, NJ 08540, U.S.A.
}

to a lesser extent, Phe. In both cell types. the conaibution of system $T$ is postulated to play a role in controlling neuroactive amine biosynthesis when transport across the plasma membrane is the rate-limiting first step in metabolism.

Relatively recent investigations of the lysosomal transport of sugars [7], nucleosides [8] and amino acids [1,9-12] have largely disproved the view that the difiusion of solute molecules through pores is the dominant means of lysosomal transport (for current reviews see Refs. 13, 14). In our laboratories, iysosomal systems that mediate amino acid fluxes continue to be discovered and characterized. Corresponding carrier proteins of the organellar membrane are analogous with those known to exist in the plasma membrane but frequen:!y show certain differences. These differences are in some cases manifest with regard to less stringent requirements on substrate geometry and the apparent lack of sensitivity to $\mathrm{Na}^{+}$for transport by the lysosomal systems [15]. Eight lysosomal transporters have so far been implicated in mediation of amino acid flux [13]. Hence, there is an increasing awareness of the role enacted by lysosomal membrane catiers in the translocation of intraceliular and intralysosomal metabolic products. This awareness logically extends to an interest in characterizing the lysosomal transporters relative to 
analogous plasma membrane transporters by biochemical and genetic means.

This report demonstrates two transport systems for aromatic and bulky dipolar amino acids in human fibroblast lysosomes resembling the $T$ and $L$ carriers present in the plasma membrane of human red blood cells and isolated rat hepatocytes. These two systems have not been previously discriminated in organellar systems, although preliminary findings have been presented [16]. This heterogeneity in the handling of bulky and aromatic dipolar amino acids by the human fibroblast lysosome differs from that observed in rat FRTL-5 cell lysosomes. In lysosomes from the FRTL-5 cell type, one transport system appears to serve for the mediation of this class of amino acids [1,17]. Differences between the transport processing of bulky and aromatic dipolar amino acids in lysosomes from the two cell types (fibroblast and thyroid) have been discerned and are reported in this work.

Eryerimeital procedures

Cell culture and preparation of lysosomal fractions. Human fetal skin fibroblasts (GM 0010, Human Genetic and Mutant Cell Repository) were grown in $850 \mathrm{~cm}^{2}$ roller bottles at $37^{\circ} \mathrm{C}$ under atmospheric conditions of $95 \%$ air $/ 5 \% \mathrm{CO}_{2}$. Cells were maintained with Coon's modification of Ham's F12 media (Hazelton Researct: Products, Inc.) supplemented with $10 \%$ fetal bovine serum (Hazelton Research Products, Inc.). Lysosomal fractions were isolated on the day of the experiment and purified on Percoll density gradients (Pharmacia P-L Biochemicals) as described by Pisoni tt al. [10]. Fibroblasts were routinely used before passage 17 , as the degree of $n$ :n-saturable uptake appeared to increase with increasing cell passage number. The usual resuspension buffer was $100 \mathrm{mM}$ citrate made iso-osmotic and buffered with $1 \mathrm{M}$ Tris to $\mathrm{pH} 7.0$.

Lysosomal uptake experiments. Two types of experiments were performed under different conditions, treatments or with inhibitor, namely time courses of lysosomal uptake and uptake at fixed tinue points. For a typical time course, a ${ }^{3} \mathrm{H}$-radiolabelled amino acid (15$140 \mathrm{Ci} / \mathrm{mmol}$, Amersham) and the appropriate amount of the same unlabelled amino acid in $0.25 \mathrm{M}$ sucrose were initially combined with inhibitors or test substances to comprise the desired condition. Uptake was initiated by adding an equal volume of ice-cold lysosomes in $100 \mathrm{mM}$ citrate/Tris to the pre-warmed radiolabelled amino acid mixture. At the selected time points, $15 \mu \mathrm{l}$ samples were withdrawn and added to $10 \mathrm{ml}$ ice-cold PBS, then rapidly filtered through GF/A glass filters (Whatman Paper Ltd.), and washed twice with 10-ml aliquots of ice-cold buffer. For uptake determinations at fixed time points, $15 \mu$ l of radiolabelled-tracer amino acid in $0.25 \mathrm{M}$ sucrose was combined with $15 \mu \mathrm{l}$ of inhibitor in $50 \mathrm{mM}$ citrate/Tris/0.125 M sucrose (pH 7.0) and warmed in a $37^{\circ} \mathrm{C}$ water bath. In kinetic experiments, increasing amounts of substate at the higher concentrations served as the inhibitor component in the incubation mixture. Ice-cold lysosomes in 100 $\mathrm{mM}$ citrate/Tris (15 $\mu \mathrm{l}, \mathrm{pH} 7.0)$ were added to begin the uptake study. Samples ( $40 \mu \mathrm{l}$ ) were withdrawn at the predetermined time interval, ejected into ice-cold PBS and collected on filters as described above.

Blanks consisted of an equal volume of $100 \mathrm{mM}$ citrate/Tris replacing the lysosomal volume in the incubation mixture. Blanks were processed in the same manner as the samples in order to determine the background radioactivity retained by the GF/A filter. This vaiue was subiracted from that of the samples. Zero points consisted of radioactivity retained on the filter after $7.5 \mu 1$ of ice-cold lysosomes were pipetted into 10 ml cold PBS, followed by $7.5 \mu \mathrm{l}$ of radioactive amino acid solution into the same tube of PBS, which was then filtered and washed twice. Filters were counted for radioactivity after adding $10 \mathrm{ml} 3 \mathrm{a} 70 \mathrm{~b}$ scintillation cocktail (Research Products International).

In order to examine uptake under infinite trans conditions, lysosomes were first incubated for $30 \mathrm{~min}$ at $37^{\circ} \mathrm{C}$ with the methyl ester of either Leu (10 mM) or Trp (1 or $10 \mathrm{mM}$ ) in $50 \mathrm{mM}$ citrate/Tris/0.125 M sucrose, then microfuged for $5 \mathrm{~min}$ at $15600 \times \mathrm{g}$ and washed twice with $20 \mathrm{mM}$ Mops containing $0.275 \mathrm{M}$ mannitol and $1 \mathrm{hg}$ bovine serum albumin/ml before final resuspension. A similar wash procedure was followed when lysosomes were pretreated with $0.25 \mathrm{mM}$ NEM/50 mM citrate/Tris/0.125 M sucrose for $15 \mathrm{~min}$ at $37^{\circ} \mathrm{C}$ in order to study the effect of thiol modification at the membrane on Leu or Trp uptake.

Latent $\beta$-hexosaminidase activity was determined for each lysosomal preparation or treatment condition and used to normalize the uptake of amino acid (in pmol) per unit of latent activity of this intralysosomal enzyme. Because reference of the uptake rate to internal organellar volume or to protein content has so far been largely unobtainable, this method is generally accepted in lysosomal transport. It permits comparison of results from experiment to experiment as well as among researchers $[7,12,18]$.

Statistics and data analysis. The nonsaturable component of amino acid uptake, $K_{\mathrm{d}}$, increased linearly with concentration $(S)$ at higher substrate levels. Analysis of initial rate data $(v)$ with a FORTRAN program using the Gauss-Newton nonlinear least-squares method [19] fit the following equation,

$\log v=\log \left\{\left[\left(V_{\max } \cdot S\right) /\left(K_{\mathrm{m}}+S\right)\right]+K_{\mathrm{d}} \cdot S\right\}$

where $K_{\mathrm{m}}$ represents the Michaelis-Menten constant and $V_{\max }$, the maximum velocity. After subtraction of the estimated nonsaturable component from initial up- 
take rate when possible, the data were transformed for analysis by both Eadie-Hofstee and double-reciprocal plot depictions.

Standard errors (S.E.) for the percent inhibited uptake rate $\left(U_{\text {inhib }}\right)$ relative to control uptake $\left(U_{\text {control }}\right)$ were calculated using

$$
\text { S.E. }\left(U_{\text {inhib }} / U_{\text {control }}\right)=\left(\text { S.E. }{ }_{\text {control }}^{2}+\text { S.E. }{ }_{\text {inhib }}^{2}\right)^{1 / 2} / U_{\text {control }}
$$

Miscellaneous. L- $\left[{ }^{3} \mathrm{H}\right]$ Tryptophan was received in a $50 \%$ ethanolic solution which was evaporated to dryness under $\mathrm{N}_{2}$ before reconstitution and use in aqueous incubation mixtures.

\section{Results and Discussion}

\section{Time courses/driving forces}

The time courses of $\operatorname{Trp}$ and $\mathrm{L}$.u lysosomal uptake are shown in Figs. 1A and 1B. Uptake was approximately linear through $1 \mathrm{~min}$ for bott compounds. All subsequent experiments at fixed timis points used incubation times of 45 or $60 \mathrm{~s}$ to ensure that uptake was occurring during the initial, linear portion of the curve. The addition of $\mathrm{NaCl}$ or $\mathrm{MgCl}_{2}+\mathrm{Na}_{2}$ ATP had no significant effect on the uptake of either aminio acid although the maximum uptake of $\operatorname{Trp}$ appeared to be somewhat slower in the presence of $\mathrm{Na}^{+}$; otherwise, the curves were superimposable within the error of the experiment.

The $\mathrm{pH}$-dependence of transport is illustrated in Fig. 2 for both Trp and Leu over the pH range of 5 to 8 . Leucine uptake steadily accelerates over this $\mathrm{pH}$ range, increasing from $0.071 \mathrm{pmol} / \mathrm{hex}$ per min at $\mathrm{pH} 5.2$ to $0.51 \mathrm{pmol} / \mathrm{hex}$ per min at $\mathrm{pH} 8.0$. Tryptophan uptake remains constant from $\mathrm{pH} 5$ to 7 , then begins to accelerate at approximately the same rate as leucine.

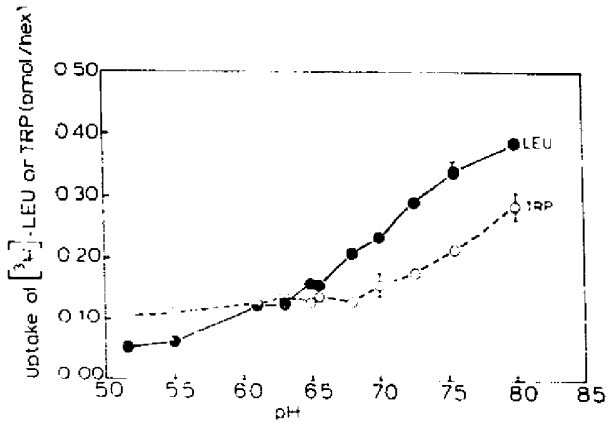

Fig. 2. $\mathrm{pH}$ profiles of $\mathrm{L} \cdot\left[{ }^{3} \mathrm{H}\right]$ tryptophan and $\mathrm{L} \cdot\left[{ }^{3} \mathrm{H}\right] \mathrm{leucine}$ uptake into lysosomes from cultured human ïbroblasts. Fibroblast lysosomes suspended in $0.3 \mathrm{M}$ sucrose $(15 \mu \mathrm{l})$ were incubated with either $15 \mu \mathrm{l}$ of $0.03 \mathrm{mM} \mathrm{L}$ L- ${ }^{3} \mathrm{H}$ !T Trp or L-[ $\left.{ }^{3} \mathrm{H}\right]$ Leu plus $15 \mu \mathrm{l}$ of $30 \mathrm{mM}$ Mes (pH 5-6.5) or Mups (pii $6.5-8$ ) buffers in $0.25 \mathrm{M}$ sucrose titrated to the desired $\mathrm{pH}$ with Tris free base. Incubations were performed at $37^{\circ} \mathrm{C}$ for $45 \mathrm{~s}$, then samples were quenched. lysosomes collected and counted for radioactivity. Samples were replicales of three or four separate incubations.

\section{Kinetics}

Characteristically, the rates of entry of Phe, Leu and Trp into the lysosome continued to rise with their concentrations. In the millimolar range this rise was almost linear to correspond to a large non-saturable component of about 5 to $7 \mathrm{pmol}$ Phe/hex per min per $\mathrm{mM}$. This component varied greatly from preparation to preparation and experiments in which the nonsaturable component was unusually large were omitted in favor of further replication. Curvilinearity is, however, observed in the micromolar range, as illustrated for the in Fig. 3. On the basis of that curvilinearity and our estimates of the rate of non-satirable uptake, we have estimated ranges for possible $K_{\mathrm{m}}$ values. From numerous kinetic studies, a consensus $K_{\mathrm{m}}$ range of 0.005 to $0.015 \mathrm{mM}$ was calculated for Phe, with the
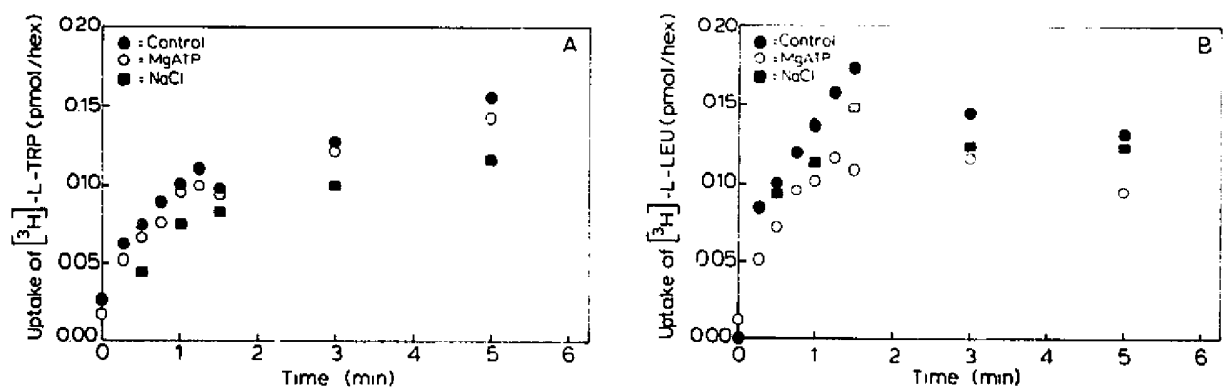

Fig. 1. (Panels A and B) Effect of $\mathrm{NaCl}$ and $\mathrm{MgATP}$ on the time courses of $\mathrm{L}-\left[^{3} \mathrm{H}\right]$ tryptophan (Panel A) and $\left.\mathrm{L}-\left.\right|^{3} \mathrm{H}\right]$ leucine (panel B) uptake into Percoll-purified lysosomes isolated from cultured human fibroblasts. The lysosomes were incubated at $37^{\circ} \mathrm{C}$ with either $0.01 \mathrm{mM}$ L- ${ }^{3} \mathrm{H} T \mathrm{Trp}$ (Panel A) or $0.01 \mathrm{mM} \mathrm{L-}\left[{ }^{3} \mathrm{H}\right] \mathrm{Leu}$ (Panel B) in $50 \mathrm{mM}$ citrate/Tris buffer ( $\mathrm{pH} 7.0$ ) containing either (a) $0.125 \mathrm{M}$ sucrose (control), (b) $62.5 \mathrm{mM} \mathrm{NaCl}$, or (c) $0.125 \mathrm{M}$ sucrose plus $2 \mathrm{mM} \mathrm{MgCl}{ }_{2}$ and $2 \mathrm{mM} \mathrm{Na} 2 \mathrm{ATP}$. As described in Experimental Procedures, samples were withdrawn from the incubation medium at the indicated time points, quenched, and the lysosomes then collected on GF/A filters and counted for radioactivity. Time courses of uptake were carried out in duplicate, except for the $\mathrm{NaCl}$ curve. 

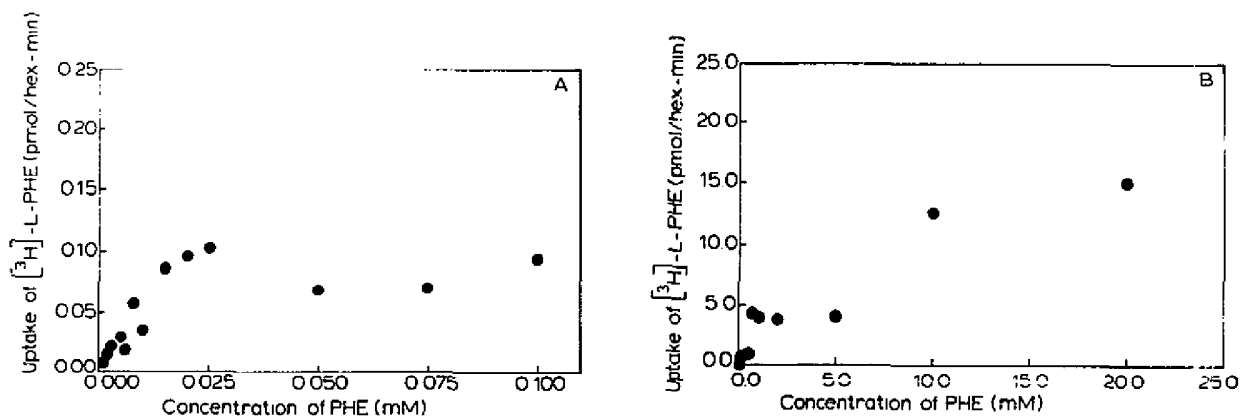

Fig. 3. (Panels $A$ and B) Initial rate kinetics of $\mathrm{L}-\mathrm{l}^{3} \mathrm{H}$ )phenylalanine uptake $\mathrm{i}$ y lysosomes from cultured human fibrublasts as a function of the concentration of phenylalanine. Fibroblasts were incubated for $1 \mathrm{~min}$ at $37^{\circ} \mathrm{C}$ with $\mathrm{L}-\left[{ }^{3} \mathrm{H}\right] \mathrm{Phe}$ plus nonradiolabelled Phe of :he indicated concentration in $50 \mathrm{mM}$ citrate/Tris buffer ( $\mathrm{pH} 7.0$ ) containing $0.125 \mathrm{M}$ sucrose. At the completion of the incubation period the lysosomes were collected and washed, and the anount of $\left[{ }^{3} \mathrm{H}\right] \mathrm{Phe}$ taken up was measured. Incubations were performed in duplicate and the results are representative of kinetic experiments repeated threc times. The Michaelis Menten piol of the initial rate of Phe uptake as a function of Phe concentration from 0 to $0.1 \mathrm{mM}$ (Panel A). Michaelis-Menten plot of the initial rate of Phe uptake as a function of Phe concentration from 0.01 to $20.0 \mathrm{mM}$ (Panel B). The nonsaturable component, $K_{\mathrm{d}}$, has not been subtracted from the data.

values for Leu and Trp being possibly twice as high. Under the conditions of these estimates, simple kinetic analysis is rendered unsuitable for distinguishing heterogereous transport and hence for identifying a homogeneous transport route [20]. Therefore, selective inhibitors were sought which could aid in determining the nature of the route(s) serving for the lysosomal passage of the large neutral amino acids.

\section{Inhibition analyses}

The first indication of heterogeneity in the transport route of the large dipolar amino acids was obtained

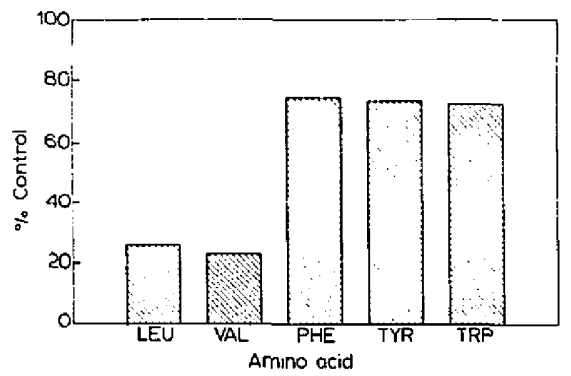

Fig. 4. Inhibition by b(+)-2-aminobicyclo[2.2.1])heptane-2-carboxylic acid of the lysosomal uptake of either $L-\left[{ }^{3} \mathrm{H}\right]$ leucine, $\mathrm{L}-\left[{ }^{3} \mathrm{H}\right]$ valine, $\mathrm{L}-\left[{ }^{3} \mathrm{H}\right]$ phenylalanine, L. $\left[{ }^{3} \mathrm{H}\right]$ tyrosine or $\left.\mathrm{L}-\mathrm{I}^{3} \mathrm{H}\right]$ tryptophan. Lysosomes from human fibroblasts were incubated for $45 \mathrm{~s}$ at $37^{\circ} \mathrm{C}$ in either $0.01 \mathrm{mM}^{3} \mathrm{H}$-labelled Leu, Val, Phe, Tyr, or Trp in $50 \mathrm{mM}$ citrate/Tris (pH 7.0).0.125 M sucrose. The $\mathrm{BCH}$ concentration was $10 \mathrm{mM}$. Uptake values are the average of two determinations. The experiment was performed twice with consistent trends in the inhibjtion patterns although different uptake values attended the two lysosomal preparations. Results are shown as a percentage of the control uptake rate performed in the absence of inhibitor. For Leu and Val the range of inhibition of control was 21 to 35\%, while for Phe, Tyr and Trp the range was 69 to $80 \%$ of control. Control uplake rates were 0.30 $\mathrm{pmol} / \mathrm{hex}$ for Leu, $0.36 \mathrm{pmcl} / \mathrm{hex}$ for Val, $0.213 \mathrm{pmol} / \mathrm{hex}$ for Phe, $0.268 \mathrm{nmol} / \mathrm{hex}$ for Tyr and $0.055 \mathrm{pmol} / \mathrm{hex}$ for Trp. using $\mathrm{BCH}$ in an effort to define the most suitable substrate for the lysosomal transporter. In Fig. 4, distinct differences between the aromatic and otherwise bulky dipolar amino acids are revealed in the pattern of inhibition by $\mathrm{BCH}$. The saturable pathway for the bulky amino acids, Leu and Val, was almost totally inhibited by $10 \mathrm{mM} \mathrm{BCH}$, whereas that of the aromatic amino acids, Phe, Tyr and Trp, was decreased by only 25 to $50 \%$ of their control uptake rates.

To refine the evidence for the role of at least two transport systems, the studies were extended to a more detailed investigation of inhibitors of Leu uptake using numerous analogs (Tables I and I1). In Table I, the compounds tested fall into three classes: (1) those sloww-

\section{TABLE 1}

Lysosomal L- $\gamma^{\prime} H$ Heucine uptake and its inhibition by analogs

All inhibitor concentrations are $10 \mathrm{mM}$ except [L-Tyr] $=0.67 \mathrm{mM}$ and [BCO] $=5 \mathrm{mM}$ owing to solubility limitations. Uptake values are the mean of three determinations with the standard enror (S.E.). The concentration of $1-\left[{ }^{3} \mathrm{H}\right]$ leucine was $0.005 \mathrm{mM}$. Results are expressed per unit latent hexosaminidase activity (' hex ${ }^{-1}$ ).

\begin{tabular}{lll}
\hline Inhibitor & $\begin{array}{l}\text { Uptake (mean } \pm \text { S.E.) } \\
\text { (pmol/hex per min) }\end{array}$ & q control \\
\hline None & $0.13 \pm 0.017$ & 100 \\
L-Leu & $0.016 \pm 0.004$ & 12 \\
L-Hle & $0.021 \pm 0.001$ & 16 \\
L-Val & $0.021 \pm 0.001$ & 16 \\
L-Met & $0.028 \pm 0.003$ & 22 \\
L-Phe & $0.032 \pm 0.001$ & 25 \\
D-Leu & $0.036 \pm 0.004$ & 28 \\
BCO & $0.049 \pm 0.005$ & 38 \\
b(+)-BCH & $0.056 \pm 0.007$ & 43 \\
L-Trp & $0.072 \pm 0.007$ & 55 \\
L-Tyr & $0.081 \pm 0.007$ & 62 \\
L-His & $0.12 \pm 0.011$ & 92 \\
MeAlB & $0.12 \pm 0.003$ & 92 \\
- & &
\end{tabular}


TABLE II

Lysosomal uptake and inhibition of L-l ${ }^{5}$ HJleucine 2

Uptake values are the mean of two determinations with the range in parentheses. The concentration of $\mathrm{L}-\left[{ }^{3} \mathrm{H}\right]$ leucine was $0.005 \mathrm{~m} \mathrm{M}$. In hibitor concentrations were $10 \mathrm{mM}$ except where indicated ntherwise. Results are expressed per unit latent hexosaminidase activitv (" hex ${ }^{-1}$ ),

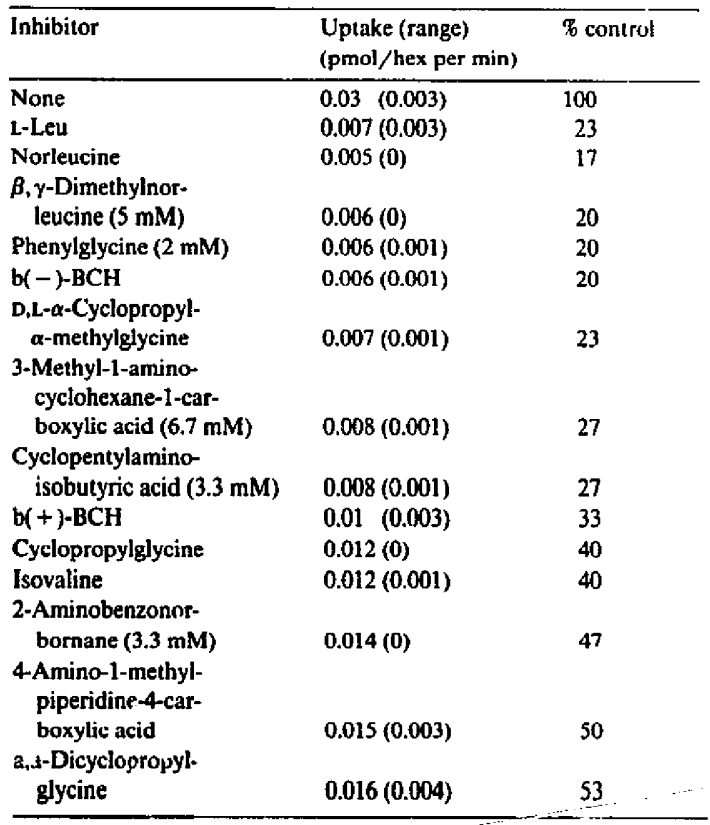

ing effective inhibition of the saturable pathway(s) (lle, Met, Val, Phe, then D-Leu); (2) those showing moderate impact in limiting leucine uptake $(\mathrm{BCO}, \mathrm{b}(+)-\mathrm{BCH}$, Trp and Tyr); (3) and those having no demonstrable effect on either pathway (His and MeAIB). More specific inhibitors of Leu uptake as well as greater knowledge of the active site requirements for the substrate were sought in the results of Table II. The Leu analogs, norleucine $(10 \mathrm{mM})$ and $N$-dimethylnorleucine $(5 \mathrm{mM})$, fell into the class of inhibitors which, within experimental accuracy, eliminated saturable uptake of Leu. It can also be seen that the effect of $b(-)-B C H$ on Leu uptake differs from that of its stereoisomer $(\mathrm{b}(+)-\mathrm{BCH}$, as described elsewhere [21], in its enhanced effectiveness as an inhibitor.

A notable characteristic of system $T$ in human red blood cells and isolated rat liver cells is affinity of the transporter for both $\mathrm{L}$ and $\mathrm{D}$ isomers of the aromatic amino acids. This lack of preference between stereoisomers was demonstrated for lysosomes by inhibition of L-Tyr uptake in Table III. The $L$ and D isomers of Phe and $\mathrm{Trp}$ eliminated the saturable component of Tyr transport (as determined by reduction of uptake in the presence of an excess of nonradiolabelled Tyr). The
TABLE 11

Inhibition of L./ ${ }^{3} H /$ tyrosine uptake into fibroblust lysosomes by $L$ and $D$ isomers of the aromatic amino acids and by bf + $-\mathrm{BCH}$

Lysosomes from human fibroblasts were incubated for 1 min at $37^{\circ} \mathrm{C}$ in $0.01 \mathrm{mM} \mathrm{c}, \mathrm{I}^{3} \mathrm{H}$ TTy in $50 \mathrm{mM}$ citrate/Tris $(\mathrm{pH} 7.0) / 0.125 \mathrm{M}$ sucrose. The inhibitor concentrations were $5 \mathrm{mM}$ except for L-Tyr which was $0.67 \mathrm{mM}$. Results are expressed as the average uptake of triplicate $1-{ }^{3}{ }^{3} \mathrm{H}$ ]Tyr incubations.

\begin{tabular}{lll}
\hline Inhibitor & $\begin{array}{l}\text { Uptake (mean } \pm \text { S.E.) } \\
\text { (pmol/hex per min) }\end{array}$ & \% control \\
\hline None & $0.060 \pm 0.002$ & 100 \\
L-Tyr & $0.015 \pm 0.005$ & 25 \\
L.Phe & $0.013 \pm 0.003$ & 22 \\
D-Phe & $0.020 \pm 0.002$ & 33 \\
L-Trp & $0.011 \pm 0.003$ & 18 \\
D-Trp & $0.017 \pm 0.005$ & 28 \\
BCH & $0.031 \pm 0.002$ & 52 \\
\hline
\end{tabular}

dextrorotatory isomer $\mathrm{b}(+)-\mathrm{BCH}$ was again seen to have a lesser inhibitory effect.

In subsequent experiments, Leu and Norleu were selected as model substrate and inhibitor, respectively, for the lysosomal system similar to system $L$ of plasma membranes, whereas L- and D-Trp served as the model substrate and inhibitor for the system similar to $T$, respectively. Table IV depicts the results of an experiment in which the lysosomal uptake of Leu or L-Trp vas inisured in the presence of $5 \mathrm{mM}$ nonradiolabelled Leu, BCH, Norleu, L-Trp or D-Trp. Results are expressed as the percentage of Leu or Trp uptake rate remaining when inhibitor is present relative to the uninhibited rate. It can be seen that BCH and Norleu reduce $\left[{ }^{3} \mathrm{H}\right]$ Leu uptake to the same extent as does adding excess unlabelled Leu itself (signifying uptake by the saturable routes), whereas $\mathrm{L}$ - and D-Trp have substantially less inhibitory impact. Conversely, D-Trp reduces

\section{TABLE IV}

Inhibition of $L-I^{3} H /$ ryptophan or $\left.L-I^{3} H\right]$ leucine uptake into fibroblast Iysosomes by L-leucine, BCH, norleucine, L-tryptophan or D-tryptophan

Human fibroblast lysosomes were incubated for $1 \mathrm{~min}$ at $37^{\circ} \mathrm{C}$ in either $\left.0.01 \mathrm{mM} \mathrm{L.f}{ }^{3} \mathrm{H}\right]$ Leu or $\mathrm{L}-\left[^{3} \mathrm{H}\right] \mathrm{Tr}$ in $50 \mathrm{mM}$ citrate/Tris $(\mathrm{pH}$ 7.0) $/ 0.125 \mathrm{M}$ sucrose. The inhibitor concentrations were $5 \mathrm{mM}$, and three incubations were performed for each condition. Results are expressed as the percentage of control uptake with the standard errors calculated as described in Experimental Procedures. Control uptakes were $0.16 \mathrm{pmol}$ Leu/hex per min and $0.12 \mathrm{pmol}$ Trp/hex per min.

\begin{tabular}{|c|c|c|}
\hline Inhibitor & $\begin{array}{l}\text { क of control } \\
{\left[{ }^{3} \text { H]Leu uptake }\right.} \\
\text { (mean } \pm \text { S.E.) }\end{array}$ & $\begin{array}{l}\text { \% of control } \\
{ }^{3} \text { HJTp uptake } \\
\text { (mean } \pm \text { S.E.) }\end{array}$ \\
\hline None & $100 \pm 2.5$ & $100 \pm 1.6$ \\
\hline L-Leu & $40 \pm 2.8$ & $53 \pm 8.2$ \\
\hline $\mathrm{BCH}$ & $45 \pm 6.2$ & $63 \pm 7.9$ \\
\hline Norleu & $34 \pm 2.8$ & $66 \pm 6.2$ \\
\hline L-TrP & $56 \pm 5.0$ & $43 \pm 1.8$ \\
\hline D-Trp & $60 \pm 2.8$ & $46 \pm 8.2$ \\
\hline
\end{tabular}




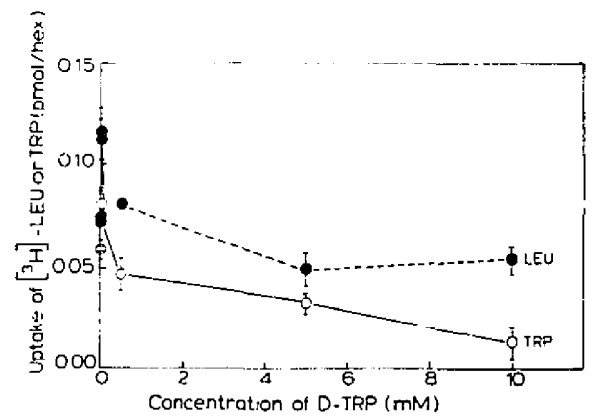

Fig. 5. Inhibition of $L-\left[{ }^{3} \mathrm{H}\right]$ tryptogithan or $\mathrm{L}-\left[{ }^{3} \mathrm{H}\right]$ leucine uplake into fibrobiast lysosomes as a function of the concentration w. tryplophan. Human fibroblast lysosomes were incubated for $1 \mathrm{~min}$ at $37^{\circ} \mathrm{C}$ in either $0.01 \mathrm{mM}{ }^{3} \mathrm{H}$-labelled L-Trp or L-Leu in $50 \mathrm{mM}$ citsate/Tris ( $\mathrm{pH} 7.0$ ) $/ 0.125 \mathrm{M}$ sucrose. The inhibited uptake of $\operatorname{Trp}$ or Leu as a function of D-Trp concentration in the range 0 to $10 \mathrm{mM}$ is shown. Each point represents the average of three determinations plus and minus the standard error. The control uptake rates wicre $0.059 \mathrm{pmol} / \mathrm{hex}$ for Trp and $0.11 \mathrm{pmol} / \mathrm{hex}$ for Leu.

$\mathbf{L}-\left[{ }^{3} \mathrm{H}\right] \mathrm{Trp}$ uptake to the level attainable with excess L-Trp whereas Leu, BCH and Norleu do not. Studies to determine how the degree of transport inhibition was related to inhibitor concentration were then pursued. Fig. 5 demonstrates that $0.05 \mathrm{mM}$ D-Trp has an inhibitory effect on both L-Leu and L-Trp uptake; however, on raising the D-Trp inhibitor concentration from 0.05 to $0.5 \mathrm{mM}$, the difference in inhibition on the two amino acids widens. By $10 \mathrm{mM}$ D-Trp, the uptake of L-Trp has been reduced to arprox. $20 \%$ of its original value while Leu retains $50 \%$ of its control uptake rate. The separate, albeit shared, relationship between the substrate/inhibitor pairs for what we provisionally will call lysosomal systems $t$ and $l$ is further illustrated in
Figs. 6A and 6B. First L- $\left[{ }^{3} \mathrm{H}\right] \mathrm{Trp}$ (Fig. 6A) and then L- $\left[{ }^{3} \mathrm{H}\right]$ Leu (Fig. 6B) were again used as substrates. Control uptake rate and nonsaturable transport rate are shown in the first two bars of each plot. In Fig. 6A, it is seen that $10 \mathrm{mM}$ Norleu has a greater inhibitory effect on L-Trp uptake than does $0.5 \mathrm{mM}$ Norleu, as would be expected. The inhibitory effect of $10 \mathrm{mM}$ Norleu is quite comparable to the same concentration of D-Trp; however, an additional effect on L-Trp uptake is seen when $0.5 \mathrm{mM}$ Norleu is combined with $10 \mathrm{mM}$ D-Trp. Inhibition is not further enhanced when the concentration of Norleu is raised to $10 \mathrm{mM}$; i.e., the additive effect is due not to the higher total inhibitor concentration but is specific to the presence of two distinct inhibitors. In Fig. 6B, neither 0.5 or $10 \mathrm{mM}$ D-Trp have an appreciable effect on Leu uptake whereas $10 \mathrm{mM}$ Norleu reduces uptake to the nonsaturable level. Accordingly, no further effect can arise with addition of D-Trp to the saturating concentration of Norleu.

\section{Trans effects}

In addition to transport being inhibitable to nonsaturable levels, the phenomenon of trans stimulation provides further evidence that carrier-mediated translocation of substrate is occurring as opposed to binding of substrate to the membrane surface without transport. Trans stimulation has been a characteristic associated with system $\mathbf{L}$ in cellular membranes from earliest descriptions [22]. In order to load the lysosomal system to high internal amino acid concentrations, the highly permeant methyl ester of the desired amino acid was incubated with the lysosomes. The free amino acid is released into the intralysosomal pool as the hydrolysis product of the esterase activity which co-purifies in the lysosomal fraction during isolation. The time course in
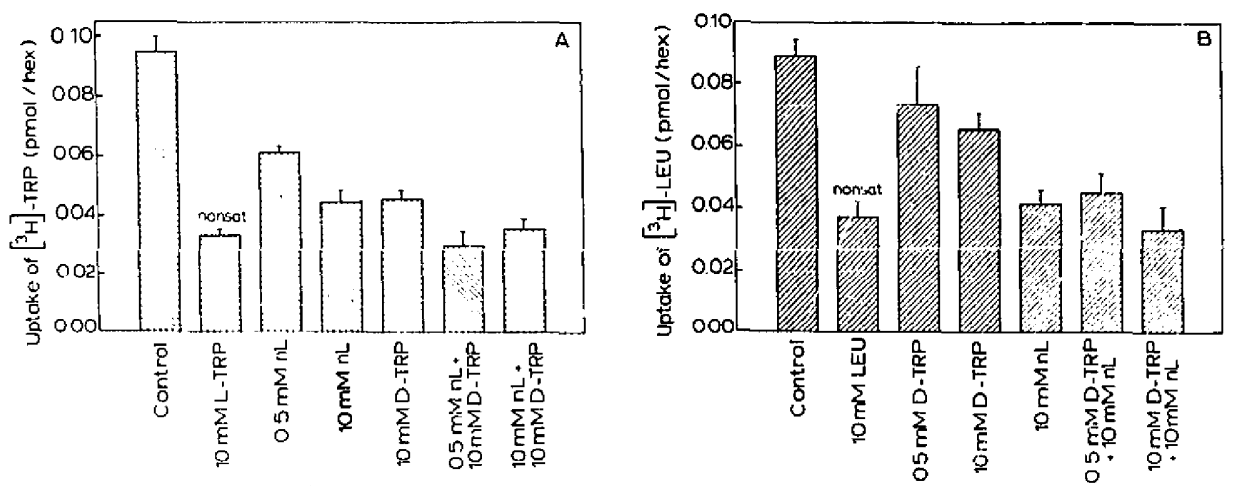

Fig. 6. (Panels A and B) Inhibition of $L-\left\{{ }^{3} \mathrm{H}\right.$ tryptophan (Panel A) or $\mathrm{L}-\left[{ }^{3} \mathrm{H}\right]$ leucine (Panel B) uptake into fibroblast lysosomes by norleucine and D-tryptophan at different combinations and concentrations of these inhibitors. Human fibroblast lysosomes w sre incubated for $45 \mathrm{~s}$ at $37^{\circ} \mathrm{C}$ in either $\left.\mathrm{L}-\mathrm{f}^{3} \mathrm{H}\right] \mathrm{Trp}$ or $\mathrm{L} \cdot\left[{ }^{3} \mathrm{H}\right] \mathrm{L}$.eu, each at $0.01 \mathrm{mM}$, in $50 \mathrm{mM}$ citrate/Tris $(\mathrm{pH} 7.0) / 0.125 \mathrm{M}$ sucrose. Inhibitor concentrations and combinations were $0.5 \mathrm{mM}$ and/or $10 \mathrm{mM}$. (Panel A) 1-Trp uptake. (Panel B) L-Leu uptake. Uptake values represent the mean of three determinations per condition plus the standard error. Nonsat, non-saturable component of uptake; $\mathrm{nL}_{\text {, norleu. }}$ 

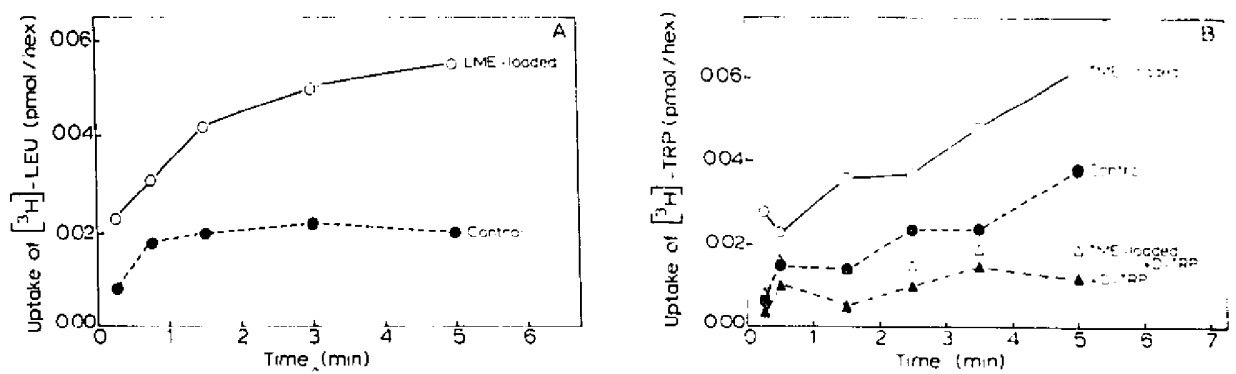

Fig. 7. (Panels A and B) Effect of trans conditions on the uptake of $1 .-\left[{ }^{3} \mathrm{H} \mid l\right.$ leucine or L-| $\left.{ }^{3} \mathrm{H}\right]$ tryptophan by fibroblast lysosomes. Percoll-purified lysosomes were loaded with L-Leu methyl ester (LME. Panel A) or L-Trp methyl ester (TME. Panel B) as described in Experimental Procedures. (Panel A) LME-loaded and nonloaded lysosomes were incubated at $37^{\circ} \mathrm{C}$ in $0.005 \mathrm{mM} \mathrm{L}-\left[{ }^{3} \mathrm{H}\right] \mathrm{Leu}$ in $50 \mathrm{mM}$ citrate/Tris $(\mathrm{pH} 7.0) / 0.125 \mathrm{M}$ sucrose. (Panel B) TME-loaded and nonloaded lysosomes were incubated at $37^{\circ} \mathrm{C}$ in $0.01 \mathrm{mM} \mathrm{L}-\left[{ }^{3} \mathrm{H}\right] \mathrm{Trp}$ in $50 \mathrm{mM}$ citrate/Tris (pH 7.0$) / 0.125 \mathrm{M}$ sucrose. The concentration of D-Trp in Panel B was $5 \mathrm{mM}$. Aliquots were removed from the incubation mixtures at the indicated times and lysosomes collected, washed and counted as described in Experimental Procedures.

Fig. 7A shows that preloaded Leu increases the uptake of Leu by a factor of 2 to 3, consistent with the carrier-mediated process identified with system L substrates. Loading lysosomes by incubation with $1 \mathrm{mM}$ L-Trp methyl ester for 30 min increases the subsequent uptake of L-Trp by 1.5-2.5-fold of the control, as shown in Fig. 7B. Inhibition of uptake into preloaded lysosomes by D-Trp $(5 \mathrm{mM})$ reduces transport to rates below those of the control rate (namely, L-Trp uptake into lysosomes under zero trans conditions), but not to the same extent that D-Trp inhibits L-Trp uptake into control lysosomes; hence, trans stimulation appears to be a faztor in both lysosomal pathways.

\section{NEM}

The results of the uptake of radiolabelled Leu, Val, Trp and Phe after treatment of the lysosomal fraction

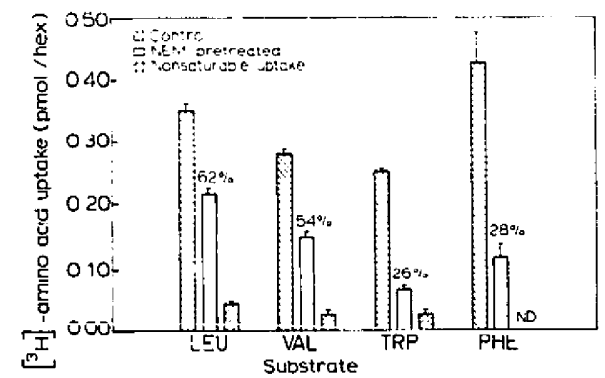

Fig. 8. Effect of pretreating fibroblast lysosomes with $N$-ethylmaleimide on uptake of ${ }^{3} \mathrm{H}$-labelled L-leucine, $\mathrm{L}$-valine, L-tryptophan or L-phenylalanine. Percoll-purified human lysosomes were treated with $0.25 \mathrm{mM}$ NEM as described in Experimental Procedures. NEM-treated and untreated lysosomes were then incubated for $45 \mathrm{~s}$ at $37^{\circ} \mathrm{C}$ in either $0.01 \mathrm{mM}^{3} \mathrm{H}$-labelled Leu, Val, Trp or Phe in $50 \mathrm{mM}$ citrate/Tris (pH 7.0) $/ 0.125 \mathrm{M}$ sucrose. The inhibitor concentration for determination of the non-saturable component was $10 \mathrm{mM}$. The mean value of three uptake determinations per condition are shown plus the standard error. \%, percent of control uptake rate for NEM-treated lysosomes; ND, not determined. with $0.25 \mathrm{mM}$ NEM are shown in Fig. 8 . The nonsaturable component was determined for the first three of these four amino acids and was low in each case, while total uptake under control conditions was relatively high. NEM moderately inhibited the mediated transport of Leu and Val (a reduction of 38 to $46 \%$ from total control uptake). two amino acids we classify as substrates favored by lysosomal system $l$; notwithstanding, NEM largely eliminated the saturable uptake of substrates favored by lysosomal system, $t$, namely L-Trp and Phe (reduction to 72 to $74 \%$ of total control rates). This distinction appears quite clear between routes for the bulky versus the aromatic substrates; however, it must be emphasized that the reproducibility of this experimen: was sensitive to variability in the magnitudes of total uptake and its nonsaturable component. These are effects which we have already associated with the approach to contiguity of the fibroblasts in culture.

\section{Additional discussion}

The ATP-driven proton pump of the lysosomal membrane maintains an outwardly directed $\mathrm{H}^{+}$gradient in vivo, resulting in an intralysosomal $\mathrm{pH}$ of approximately $5[23-25]$. The role of this gradient as a driving force in lysosomal accumulation of weak bases is a acidotropic phenomenon [26], which is distinct from active or cotranspori piocesses. In order to regenerate the $\mathrm{FH}$ gradient in freshly isolated lysosomes. ATP was added to the incubation media. No significant effect on the uptake of Trp and Leu was observed under these conditions, implying independence from the outwardly directed $\mathrm{H}^{+}$gradient. As would be expected, differences in lysosomal efflux and influx in the presence of ATP have been seen for amino acids of net charge, Arg [11] and Lys [9], and for cystine [12], but not for the zwitterionic Pro [10]. Changing the $\mathrm{pH}$ of the incuba- 
tion medium over the range of $\mathrm{pH} 5$ to 8 increased the uptake rate of Leu substantially while Trp uptake did not increase until approximately $\mathrm{pH} 7$. The change in ionization state for these amino acids is less than $1 \%$ over this pH range. Along with the iack of ATP requirement, this result suggests that it is the transporter molecule that is sensitive to $\mathrm{pH}$ changes. Such does not appear to be the case in human or pigeon red blood cell transport of Trp and I eu [3] or in human placental brush-border vesicle uptake of Trp [27] where only a very slight downward or no effect at all on rate is seen with rising $\mathrm{pH}$. Mitsumoto at at. [28] have reported stimulation of Leu uptake by plasma membrane vesicles from Chang liver cells in the presence of an inwardly directed $\mathrm{H}^{+}$gradient. As with other amino acids thus far studied, Leu and Trp also fail to show a requirement for $\mathrm{Na}^{+}$in the extralysosomal medium.

Several lines of evidence support the duality in lysosomal transport of bulky and aromatic dipolar amino acids; nonetheless, clear discrimination between the two systems, as has been accomplished with the apparently analogous plasma membrane carriers using $\mathrm{BCH}$ and D-Trp, has been more difficult than usual in the lysosomal system. For instance, it was not possible to difierentiate the shared carrier systems with simple oneor two-component kinetic plots as has been done with isolated rat hepatocytes using $\mathrm{BCH}$ [5]. This difficulty appeared to arise in part from the greater overlap of amino acid affinities in the lysosomal transport process, further complicated by larger experimental variance. The kinetics were well described by a model involving transport by a sing!e carrier site. $K_{\mathrm{m}}$ values for each of the substrates were in the range of $0.005-0.02 \mathrm{mM}$. The similarity in the magnitudes of the $K_{\mathrm{m}}$ values possibly explain the inability of the simplest kinetic modeling to discriminate the two transport components, now recognized as a frequent problem [29].

The component of lysosomal Ala transport inhibitable by Leu and provisionally designated $e[10]$ should also be considered as possibly contributing to the heterogeneity observed here for the transport of branchedchain amino acids. Component $e$ serves as a major route for lysosomal transport of $\mathrm{Ala}$, Ser and Thr, but Leu transport by system $e$ may be considered possible. Accordingly, the relation between the components designated $c$ and $l$ remains to be established as to overlap or even conceivable identity.

Several criteria for defining parallel lysosomal transport systems similar to the $\mathbf{T}$ and $\mathbf{L}$ dichotomy in the plasma membrane were examined by inhibition analyses. The tests were conducted to obtain information with respect to binding site requirements and specificity. Leucine uptake was inhibited by a number of analogs which have previously been shown to compete for the system $L$ carrier $[21,30]$. Tolerance, if not preference, for bulky side-chains in the form of structures such as the norbornane ring which bears a planar extension in aminobenzonorbornane and 4-amino-1-methyl-piperidine-4-carboxylic acid, and also for dicyclopropylglycine was observed [31]. This finding may imply a less rigorous structural requirement at the binding site, parallel to that observed in the lysosomal transport of the dicarboxylic acids [15]. Norleucine inhibition of Leu uptake appeared more specific than that by $\mathrm{BCH}$, used classically as a system $L$ inhibitor. A distinguishing anomaly of system.T.T red blood cells and isolated hiepatocytes is its affinity for the $D$ isomers of the aromatic amino acids, in particular, D-Trp. Contention exists as to whether or not [-Trp is actually translocated in those cells and if so, whether this occurs by a saturable process; the consensus, however, holds that D-Trp interaction with the T carrier is competitive $[4,5]$. In the lysosomal system, D-Trp was an effective inhibitor of L-Trp uptake. The impact of D-Trp inhibition on Leu uptake was suggestive of the extent of system t-contribution to Leu uptake (Figs. 6A and 6B). This result is in contrast to that obtained by Bernar et al. [1], where D-Tyr only marginally inhibited the uptake of L-Tyr into lysosomes from FRTI,-5 thyroid cells. Tyrosine and Trp have similar affinities for system $T$ where it is present [2], so this discrepancy between results may be due to the different origins of the lysosomal fractions used (human fibroblasts versus rat thyroiu FRTL-5 cells).

The clearest difference between the transport processing of the two groups of amino acids was seen when lysosomal fractions were pretreated with the sulfhydryl-reactive agent, $N$-ethylmaleimide, at 0.25 $\mathrm{mM}$. Although NEM is known to interact with the lysosomal $\mathrm{H}^{+}$-ATPase pump [25], it can be construed from our earlier discussion that this would not have a direct effect on the transport of these amino acids. It appears that NEM preferentially inactivates the carrier responsible for the major part of Trp and Phe uptake. This finding is consistent with the behavior observed in human red blood cells [3] but not in lysosomes isolated from rat thyroid cells [1]. Chiles et al. [32] have reported a lack of NEM sensitivity for amino acid transporters in four hepatoma cell lines as an apparent characteristic of the cell transformation. This generalization may partially explain the lack of a NEM effect in continuously cultured FRTL-5 cells; the human fibroblasts used in these experiments can be subcultured a finite number of times and are not considered transformed. Again, the disparity between the two lysosomal systems may be best explained in terms of cellular origin.

\section{Acknowledgments}

This work was supported by Grants No. DK33281 and HD01233, the National Institutes of Health. 


\section{References}

1 Bernar, J., Tietze, F., Kohn, L.D., Bernardini. I.. Harper. G.S.. Grollman, E.F. and Gahl, W.A. (1986) J. Biol. Chem. 261. 17107-17112.

2 Rosenberg, R., Young, J.D. and Ellory, J.C. (1980) Biochim. Biophys. Acta 598, 375-384.

3 Vadgama, J.V. and Christensen, H.N. (1985) J. Biol. Chem. 260. 2912-2921.

4 Lopez-Burillo, S., Garcia-Sancho, J. and Herreros, B. (1985) Biochim. Biophys. Acta $829,85-y 4$.

5 Salter, M.. Knov,les, R.G. and Pogson, C.I. (1986) Biochem. J. 233, 499-500.

6 Weissbach, L., Handlogten, M.E., Christensen, H.N. and Kilberg. M.S. (1982) J. Biol. Chem. 257, 12006-12011.

7 Bird, S.J., Forster, S. and Lloyd, J.H. (1987) Biochem. J. 245, 929-931.

8 Pisoni, R.L. and Thoene, J.G. (1988) FASF.B J. 2, MiT4j.

9 Pisoni, R.L., Thoene, J.G. and Christensen, H.N. (1985) J. Biol. Chem. 260, 4791-4798.

10 Pisoni, R.L., Flickinger, K.S., Thoene, J.G. and Christensen. H.N. (1987) J. Biol. Chem. 262, 6010-6017.

11 Pisoni, R.L., Thoene, J.G., Lemons, R.M. and Citristensen, H.N. (1987) J. Biol. Chem. 262, 15011-15018.

12 Smith, M.L., Greene, A.A., Potshnik, R., Mendoza, S.A. and Schneider, J.S. (1987) J. Biol. Chem. 262, 1244-1253.

13 Christensen, H.N. (1988) Biosci. Rep. 8, 121-129.

14 Forster, S. and Lloyd, J.B. (1988) Biochim. Biophys. Acta 947, 465-491.

15 Collarini, E.J., Pisoni, R.L. and Christensen, H.N. (1988) FASEB J. 2, A322.

16 Stewart, B.H., Collarini, E.J., Pisoni, R.L. and Christensen. H.N. (1988) FASEB J. 2, A322.
17 Harper, G.S., Kohn. L.D. Bernardini, 1., Bernar, J., Tietze. F., Andersson, H.C. and Gahl. W.A. (1988) J. Biol. Chem. 263. 9320-9325.

18 Gahl, W.A., Tietze, F., Bashan. N.. Bernardini. I.. Raiford, D. and Schiulioun, 3.D. (i 983) Biochem. J. 216. 393-400.

19 Cleland. W.W. (1979) Methods Enzymol. 63. 103-138.

20 Pisoni, R. L. and Thoene, J.G. (1989) J. Biol. Chem. $264.4600-4856$

21 Tager, H.S. and Christensen. H.N. (1971) J. Broi. Chem. 246, $7572-7580$.

22 Oxender, D.L. and Cinristensen, H.N. (1963: J. Biol. Chem. 238. 3686-3699.

23 Ohkuma, S., Moryama. Y. and Takamo. T. (1982) Proc. Nati. Acad. Sci. USA 79, 2758-2762.

24 Harikumar, P. and Reeves, R.P. (1983) J. Biol. Chem. 258. 10403-10410.

25 Cupoletti. J., Aures-Fisher, D. and Sachs, S. (1987) Biochim. Biophvs. Acta 899. 270-284.

26 De Duve, C.. De Barsy. T., Poote. B., Trouet, A.. Tulkens, P.. Van Hoof. F. (1974) Biochem. Pharmacol, 23, 2495-2531.

27 Ganapathy, M.E., Leibach, F.H.. Mahesh, V.B., Howard, J.C. Devoe, L.D. and Ganapathy, V. (1986) Biochem. J. 238, 201-208.

28 Mitsumoto, Y., Sato, K.. Ohyashiki, T. and Mohri, T. (1986) J. Biol. Chem. 261, 4549-4554.

29 Christensen. H.N. (1985) J. Membr. Bicl. 84, 97-103.

30 Christensen, H.N. (1975) in Biological Transport, 2nd Edn. pp. 176-187. W.A. Benjamin, Inc., Reading MA.

31 Christcnsen. H.N. and Handlogten. M.E. (1968) J. Biol. Chem. 243, 5420-5438.

32 Chiles, T.C., Dudek-Collart, K.L. and Kilberg. M.S. (1988) Am. J. Physiol. 255 (Cell Ptyysiol. 24), C340-C345. 